\title{
HBV Facilitated Hepatocellular Carcinoma Cells Proliferation by Up-Regulating Angiogenin Expression Through IL-6
}

\author{
Xiaotang Zhou Fan Yang Ying Yang Ying Hu Weixia Liu Chunhong Huang \\ Shuping Li Zhi Chen
}

State Key Laboratory of Infectious Disease Diagnosis and Treatment, Institute of Infectious Diseases, First Affiliated Hospital, School of Medicine, Zhejiang University, Collaborative Innovation Center of Infectious Disease Diagnosis and Treatment, Hangzhou, Zhejiang, P. R. China

\section{Key Words}

Hepatitis B virus • Hepatocellular carcinoma • Angiogenin • Interleukin-6

\begin{abstract}
Background/Aims: Patients with hepatitis B virus (HBV) infection are at a high risk of developing hepatocellular carcinoma (HCC). In this study, we aim to investigate the roles of $\mathrm{HBV}$ on angiogenin (ANG), as well as the effects on cell proliferation in presence of ANG down-regulation. Methods: Serum ANG was determined by ELISA. The expression of ANG mRNA and protein in HCC cell lines with or without HBV/HBx were determined. Western blot and ELISA were conducted to determine the effects of HBV/HBx on IL-6 expression. The role of IL- 6 on ANG was evaluated by IL- 6 recombinant protein or IL- 6 neutralizing antibody. Immunofluorescence staining was used to detect the nuclear translocation of ANG. MTT was performed to evaluate the relative inhibition ratio. Result: In vivo experiments showed elevation of serum ANG in patients infected with HBV. In vitro experiments showed HBV and $\mathrm{HBx}$ contributed to the transcription and translation of ANG. ANG expression showed increase after IL- 6 stimulation, and ANG protein decreased in the presence of IL- 6 blocking with its antibody. HBV promoted nuclear translocation of ANG. Inhibiting ANG expression or blocking of nuclear transfer of ANG attenuated the 45S rRNA synthesis and cell proliferation. Conclusion: HBV and HBx protein can increase the level of ANG through IL-6. HBV and HBx contributed to the nuclear translocation of ANG. Cell proliferation was inhibited after inhibiting the expression or nuclear transfer of ANG.

\section{Introduction}

Hepatitis B virus (HBV) infection is a worldwide health problem [1] affecting about 240 million persons until 2005 [2]. Although HBV infection rate has been significantly reduced with the utilization of vaccines, HBV-related mortality is severe worldwide as up to 1 million people died from chronic HBV-related complications [3], such as chronic hepatitis, cirrhosis,

Prof. Zhi Chen and Prof. Shuping Li
State Key Laboratory of Infectious Disease Diagnosis and Treatment, First Affiliated Hospital Zhejiang University, No. 79 Qingchun Road Hangzhou, Zhejiang 310003 (P. R. China) Tel.+86-0571-87236579, E-Mail zjuchenzhi@zju.edu.cn, li.shuping08@gmail.com 


\section{Cellular Physiology Cell Physiol Biochem 2018;46:461-470 \begin{tabular}{l|l} 
and Biochemistry Published & $\begin{array}{l}\text { DOI.1159/000488614 } \\
\text { Po } 2018 \text { The Author(s). Published by S. Karger AG, Basel } \\
\text { www.karger.com/cpb }\end{array}$ \\
\hline
\end{tabular} \\ Zhou et al.: HBV Promotes HCC via Angiogenin}

acute liver failure (ACLF), and particularly hepatocellular carcinoma (HCC) [4]. Nowadays, the majority of HCC (up to 75\%), considered as one of the most common malignancies among human cancers [5, 6], is caused by chronic HBV or HCV infection [7]. Since the first report on the relation between HBV and HCC in 1970 [8], extensive aspects have been considered to be responsible for the HBV-induced HCC, including genetic damages by immune-mediated hepatic inflammation, oxidative stress, a virus-specific mechanism involving the viral proteins $\mathrm{HBV} \mathrm{X}(\mathrm{HBx})$ and $\mathrm{HBs}$, as well as the insertional mutagenesis with integration of HBV DNA into the host genome [9]. Among them, HBx protein is thought to be the most crucial factor in hepatocarcinogenesis $[10,11]$, and has been reported to be closely related to the pathogenesis of HCC by modulating several cell signaling pathways, such as p53, PI3K/ AKT, and NF- $\kappa B$ pathways $[12,13]$. In addition, it can also affect the expression of miR-21 [14], miR-18a [15], miR-145 [16], and miR-122 [17].

Angiogenin (ANG), a $14 \mathrm{kDa}$ protein consisted of 123 amino acids, is the fifth member of ribonuclease A superfamily (RNASE5) [18]. To date, it has been proved to be upregulated in many human cancers such as prostate cancer [19], breast cancer [20], colorectal cancer [21], gastric cancer [22], brain tumor [23], lung cancer [24], and liver cancer [25]. It was reported to involve in several biological processes such as rRNA production [26], tiRNA production in the presence of stress [27], as well as cancer cell proliferation [28]. In a previous study, Sadagopan et al. reported that Kaposi's sarcoma associated herpesvirus (KSHV) involved in up-regulation of ANG, which then contributed to the ANG-induced 45S rRNA synthesis, antiapoptosis, cell proliferation, migration, angiogenesis, and finally promoted tumorigenesis [29]. Additionally, EDN and ECP (two members of ribonuclease A superfamily) showed negative effects on RSV [30], among which EDN could also protect against HIV-1 infection [31]. These findings lead us to investigate the relationship between ANG and HBV-related HCC.

In this study, we determined the serum ANG expression in HBV-infected patients and healthy controls. On this basis, the mechanism of ANG up-regulation mediated by HBV and its effects on cell proliferation were further elucidated by in vitro experiments.

\section{Materials and Methods}

\section{Sample collection}

Specimens were obtained from 140 participants presented to the First Affiliated Hospital of Zhejiang University from March 2010 to April 2011 including health controls (n=32) recruited from health examinations with hepatitis, asymptomatic carriers (ASC) of $\mathrm{HBV}(\mathrm{n}=38)$, patients with mild chronic hepatitis B infection (CHB-M) $(n=38)$, as well as patients with severe chronic hepatitis B infection (CHB-S) $(\mathrm{n}=32)$. Venous blood samples $(2 \mathrm{~mL})$ were collected from each participant and then serum was obtained after centrifugation at 3,000 rpm for $15 \mathrm{~min}$. Subsequently, the supernatant was collected, followed by centrifugation at $12,000 \mathrm{rpm}$ for $5 \mathrm{~min}$. All serum samples were stored at $-80^{\circ} \mathrm{C}$. Each participant signed the informed consent. The study protocols were approved by the Ethical Committee of First Affiliated Hospital of Zhejiang University.

\section{Regents and Antibodies}

Serum and supernatants ANG were tested by Human Angiogenin ELISA Kit (DAN00, R\&D, USA). Neomycin (N6386) and paromomycin (P9297) were purchased from Sigma-Aldrich (Sigma, USA). Recombinant Human IL-6 protein (7270-IL-025/CF) were bought from R\&D (CA, USA). The siRNA for silencing ANG (sc39291) and control siRNA (sc37007) were purchased from Santa Cruz (MI, USA). The antibodies used in this study were as follows: Mouse anti-angiogenin (1:500 dilution, ab10600, Abcam, USA), rabbit anti-IL6 (1:500, ab6672, Abcam, USA), rabbit anti-histone H3 (1:2000, \#4620, Cell Signaling Technology, USA) and mouse anti- $\beta$-actin $(1: 3000,4970$, Cell Signaling Technology, USA).

Cell culture, transfection and treatments

HCC cell lines (i.e. HepG2 and Huh7) were cultured in Dulbecco's modified Eagle medium (DMEM) containing 10\% fetal bovine serum (FBS, Gibco, USA). HepG2.2.15 cells stably expressing HBV were cultured 


\section{Cellular Physiology Cell Physiol Biochem 2018;46:461-470 and Biochemistry Published online: April 03, $2018 \quad \begin{aligned} & \text { DOI 10159/2018 The Author(s). Published by S. Karger AG, Basel } \\ & \text { www.karger.com/cpb }\end{aligned}$ \\ Zhou et al.: HBV Promotes HCC via Angiogenin}

in DMEM containing 10\% FBS, and then G418 (380 mg/mL, Sigma-Aldrich, CA, USA) was added. Transient transfection was performed with pcDNA3.1-HBV and pcDNA3.1-EGFP-HBx plasmids using lipofectamine 2000 according to the manufacturer's instructions (Invitrogen, USA). Cells transfected with pcDNA3.1 and pcDNA3.1-EGFP served as control.

\section{RNA interference assay}

HepG2 cells were seeded on 24-well plates and incubated overnight. Then the cells were treated using ANG-specific small interfering RNA and control siRNA, respectively. A concentration of 50nM was selected for Lipofectamine RNA imax (Invitrogen, USA). Cells were harvested 48 hrs after transfection for further analysis.

\section{Real-Time PCR analysis}

Total RNA was extracted from HCC cells using Trizol reagent (Takara, Japan) according to the manufacturer's instructions. The cDNA synthesis was performed using $1 \mu \mathrm{g}$ total RNA using PrimeScript RT reagent Kit (Takara, Japan). Real-Time PCR was used for the amplification using SYBR Premix (RD, USA) according to the manufacturer's instructions. The amplification conditions included denaturation at $95{ }^{\circ} \mathrm{C}$ for $2 \mathrm{~min}$, followed by 40 cycles of $95^{\circ} \mathrm{C}$ for $15 \mathrm{sec}$ and $62^{\circ} \mathrm{C}$ for $60 \mathrm{sec}$. The mRNA level was normalized by GAPDH. The relative expression level was determined according to the $2^{-\Delta \Delta \mathrm{Ct}}$ method. The specific primers used in the proliferation was listed as follows:

GAPDH: 5'-GAAATCCCATCACCATCTTCCAGG-3' (forward),

5'-GAGCCCCAGCCTTCTCCATG-3' (reverse);

ANG: 5'-ACCCATCTCCAGGAACAAAC-3' (forward),

5'- TCACCATCTCTTCCAACACAG-3' (reverse);

45S rRNA : 5'- CGGGTTATTGCTGACACGC-3'(forward),

5' - CAACCTCTCCAGCGACAGG-3' (reverse).

\section{Immunofluorescence assay}

Cells $\left(2 \times 10^{4}\right)$ were seeded on glass coverslips in 24-well plates. About $48 \mathrm{hrs}$ later, the cells were washed with cold PBS twice, and then fixed with pre-cold methanol at $-20^{\circ} \mathrm{C}$ for $10 \mathrm{~min}$. After washing with PBS twice, the mixture was blocked in PBS containing $30 \mathrm{mg} / \mathrm{ml}$ BSA at $37^{\circ} \mathrm{C}$ for $10 \mathrm{~min}$ twice. Subsequently, the mixture was incubated with 26-2F (ANG antibody, made in house, $30 \mu \mathrm{g} / \mathrm{ml}$ ) in PBS containing $5 \mathrm{mg} / \mathrm{ml}$ of BSA at $4^{\circ} \mathrm{C}$ overnight. After incubating with Alex 488 anti-mouse antibody (1: 500, A11001, Invitrogen, USA) in PBS containing BSA ( $5 \mathrm{mg} / \mathrm{ml}$ ) at $37^{\circ} \mathrm{C}$ for $1 \mathrm{hr}$, the mixture was washed with PBS containing BSA $(5 \mathrm{mg} / \mathrm{ml})$ at $37^{\circ} \mathrm{C}$ for $10 \mathrm{~min}$ for 5 times. Afterwards, nuclear staining dye TO-PRO®-3 (1: 300, S33025, Invitrogen, USA) was added, and then incubated for 15 minutes at room temperature. Finally, the images were observed under a confocal microscopy (Olympus Inc, Center Valley, PA, USA).

\section{Western blot analysis}

HCC cells were lysed with $50 \mu \mathrm{L}$ RIPA for $10 \mathrm{~min}$ on ice. The cell lysates were centrifuged at $12,000 \mathrm{~g}$ at $4^{\circ} \mathrm{C}$. Nucleoprotein were extract from HepG2.215 cells using nuclear and cytoplasmic extraction reagents (78833, ThermoFisher Scientific, CA, USA). Protein ( $50 \mu \mathrm{g}$ ) was separated by SDS-PAGE and then transferred to PVDF membranes (Bio-Rad, USA). The membranes were incubated with the antibodies overnight at $4^{\circ} \mathrm{C}$ after being blocked with $5 \%$ non-fat milk for $1 \mathrm{hr}$. The membranes were washed with $1 \times$ TBS-Tween 3 times and incubated with secondary antibodies at room temperature for $2 \mathrm{hrs}$. Protein was analyzed with chemiluminescent detection. The relative expression of ANG and IL- 6 was normalized by $\beta$-actin, and the relative expression of ANG nucleoprotein was normalized by histone H3.

\section{MTT assays}

To further confirm the effects of ANG on HepG2.2.15 or HepG2, cells were seeded on a 96-well plate at a density of $3 \times 10^{4}$ per well. The attached cells were pretreated with neomycin/paromomycin, IL-6/IL-6 Ab or ANG siRNA, and then were subject to MTT [3-(4, 5-dimethylthiazol-2-yl)-2, 5-diphenyltetrazolium bromide] assay. Then $10 \mu \mathrm{l}$ MTT reagent (Millipore, Billerica, MA, USA) was added to each well. After incubating for 4 hrs, cells were lysed by adding $200 \mu \mathrm{L}$ DMSO. Absorbance was measured at a wavelength of $570 \mathrm{~nm}$. 


\section{Cellular Physiology Cell Physiol Biochem 2018;46:461-470

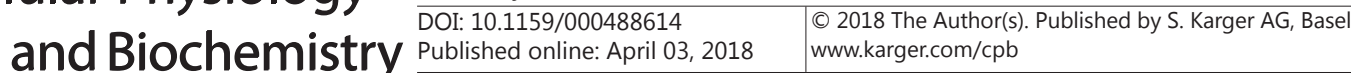 Zhou et al.: HBV Promotes HCC via Angiogenin}

\section{Statistical analysis}

All data were analyzed with SPSS version 16.0. Data were presented as mean \pm standard deviation (SD). Each experiment was repeated at least three times. The differences between two groups were compared using Student's t-test. $\mathrm{P}<0.05$ was considered to be statistical significance.

\section{Results}

The serum ANG increased in patients infected by HBV

As shown in Table 1, no significant difference was observed in age and gender ratio among three groups. Serum ANG was measured by ELISA. As shown in Fig. 1, serum ANG showed significant increase in ASC and CHB-M groups compared to that of healthy controls. In contrast, no statistical difference was noticed in serum ANG among ASC, CHB-M and CHB-S patients. These indicated that HBV infection might contribute to the elevation of serum ANG.

$H B V$ contributed to the elevation of ANG mRNA and protein level in HepG2.2.15 cells

To confirm whether HBV infection may contribute to the elevation of serum ANG, we examined the ANG level in HepG2.2.15 and Huh7 cells transfected with pcDNA3.1-HBV (Huh7-

Table 1. ASC: asymptomatic HBV Carriers, CHB-M: mild chronic hepatitis B, CHB-S: severe chronic hepatitis B , ALT: alanine aminotransferase, AST: aspartate aminotransferase. ${ }^{a} \mathrm{P}$ value of one-way ANOVA. ${ }^{\mathrm{b}}$ Chisquare test

\begin{tabular}{|c|c|c|c|c|c|}
\hline Clinical characteristics & Healthy controls $(\mathrm{N}=32)$ & $\begin{array}{c}\text { ASC } \\
(\mathrm{N}=38)\end{array}$ & $\begin{array}{l}\text { CHB-M } \\
(\mathrm{N}=38)\end{array}$ & $\begin{array}{c}\text { CHB-S } \\
(\mathrm{N}=32)\end{array}$ & $P$ value \\
\hline Age & $37.44 \pm 11.19$ & $37.87 \pm 12.62$ & $37.39 \pm 15.11$ & $40.34 \pm 10.72$ & $0.138^{\mathrm{a}}$ \\
\hline Sex ratio (male/female) & $18 / 14$ & $19 / 19$ & $25 / 13$ & $16 / 16$ & $0.176^{\mathrm{b}}$ \\
\hline ALT & $26.41 \pm 9.49$ & $24.84 \pm 11.12$ & $41.53 \pm 33.16$ & $332.91 \pm 202.22$ & $0.000^{\mathrm{a}}$ \\
\hline AST & $18.38 \pm 3.69$ & $24.21 \pm 7.93$ & $26.92 \pm 11.87$ & $305.43 \pm 216.87$ & $0.000^{\mathrm{a}}$ \\
\hline
\end{tabular}

Fig. 1. Serum ANG was elevated in healthy control individuals (HC, $\mathrm{n}=32$ ), asymptomatic HBV carriers (ASC, $n=38$ ), mild chronic hepatitis $B$ patients (CHB-M, $n=38$ ), severe chronic hepatitis B patients (CHB-S, $\mathrm{n}=32$ ). ${ }^{* *} \mathrm{P}<0.01$, compared with the normal group.

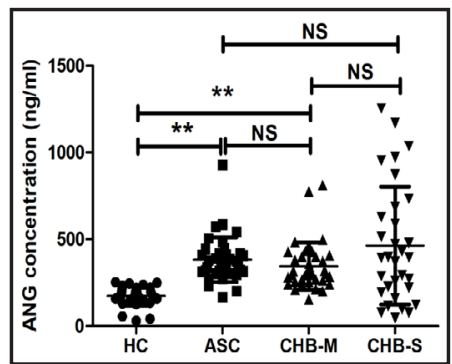

Fig. 2. HBV replication upregulated $A N G$ expression in vivo. ( $A$ and $B$ ) The mRNA levels of ANG in HepG2.2.15 and Huh7-HBV cells were determined by Real-Time PCR, and then were compared to HepG2 or Huh7-con cells. (C) ANG concentration in supernatant of HepG2 cells and HepG2.2.15 cells. (D) ANG concentration in supernatant of Huh7-con and Huh7-HBV cells. (E) ANG protein expression in HepG2 cells and HepG2.2.15 cells by Western Blot assay. (F) Western Blot assay of ANG protein in Huh7-con and Huh7-HBV cells. $\left({ }^{*} \mathrm{P}<0.05,{ }^{* *} \mathrm{P}<0.01\right)$.

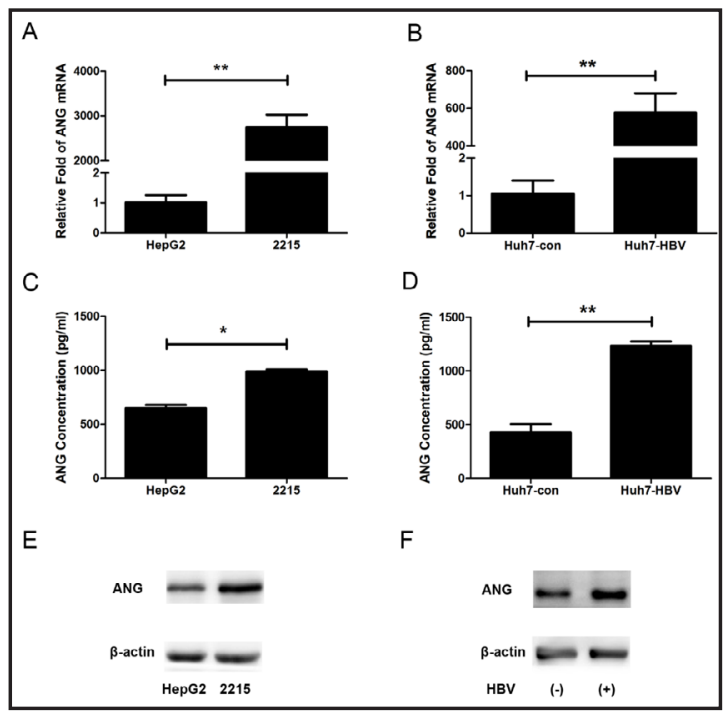


Fig. 3. HBx upregulated ANG expression in HepG2 cells. HepG2 cells were transfected with HBx plasmid or control plasmid, mRNA, supernatant and protein were harvested 48 hours after transfection. (A and B) The mRNA levels of ANG, the relative fold were determined by Real-Time PCR. (C and D) ANG concentration in supernatant. ( $\mathrm{E}$ and $\mathrm{F}$ ) The protein level of ANG. $\left({ }^{*} \mathrm{P}<0.05,{ }^{*} \mathrm{P}<0.01\right)$.

HBV). HepG2 and Huh7 cells transfected pcDNA3.1 (Huh7-con) served as control. Real-Time PCR indicated that ANG mRNA in HepG2.2.15 and Huh7-HBV showed significant increase compared to that in HepG2 and Huh7-con $(\mathrm{P}<0.05$, Fig. 2A and 2B). As shown in Fig. 2C and 2D, ANG in supernatants of HepG2.2.15 cells and Huh7-HBV showed significant

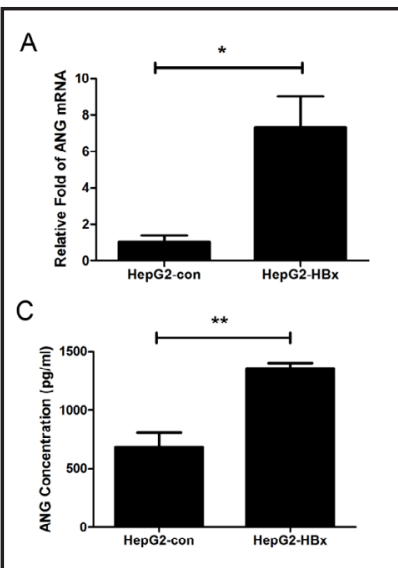

E

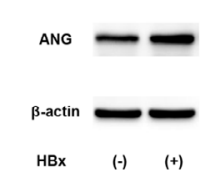

B

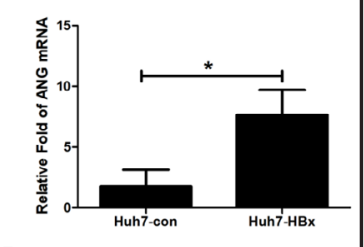

D

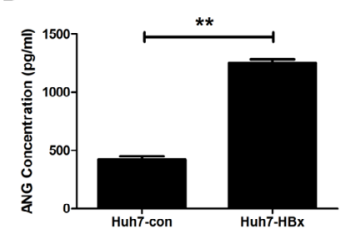

$\mathrm{F}$

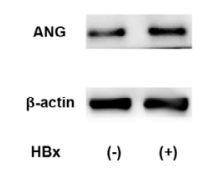
increase compared to HepG2 cells and Huh7-con $(\mathrm{P}<0.05)$. Meanwhile, cytoplastic ANG expression in HepG2.2.15 and Huh7HBV was higher than HepG2 and Huh7-con through (Fig. 2E and 2F).

$H B x$ promoted the expression of $A N G$ in HepG2

To identify the putative composition of HBV that increased the ANG level, HepG2 and Huh7 cells were transfected with pcDNA3.1EGFP-HBx. Fig. 3 showed the ANG mRNA and protein levels were up-regulated after transfection. This suggested that HBx may involve in mediating the HBV-induced ANG uptake.

\section{$H B V / H B x$ increased $A N G$ through raising} the level of IL-6

To further investigate how $\mathrm{HBV} /$ HBx involved in the regulation of ANG, we measured the IL-6 protein. IL-6 expression was upregulated in HepG2.2.15 cells or HepG2 cells transfected with HBx plasmid (Fig. 4A and 4B). Furthermore, IL-6 (50ng/ $\mathrm{ml}$ ) contributed to the up-regulation of both ANG mRNA and protein in these cells (Fig. 4C-4F). Conversely, when treating with IL-6 neutralizing antibody $(1: 400)$ for $48 \mathrm{hrs}$, the ANG level in HepG2.2.15 cells was reduced (Fig. 4G and $4 \mathrm{H}$ ). These results suggested that up-regulation of ANG by $\mathrm{HBV} / \mathrm{HBx}$ may be associated with elevation of IL-6.

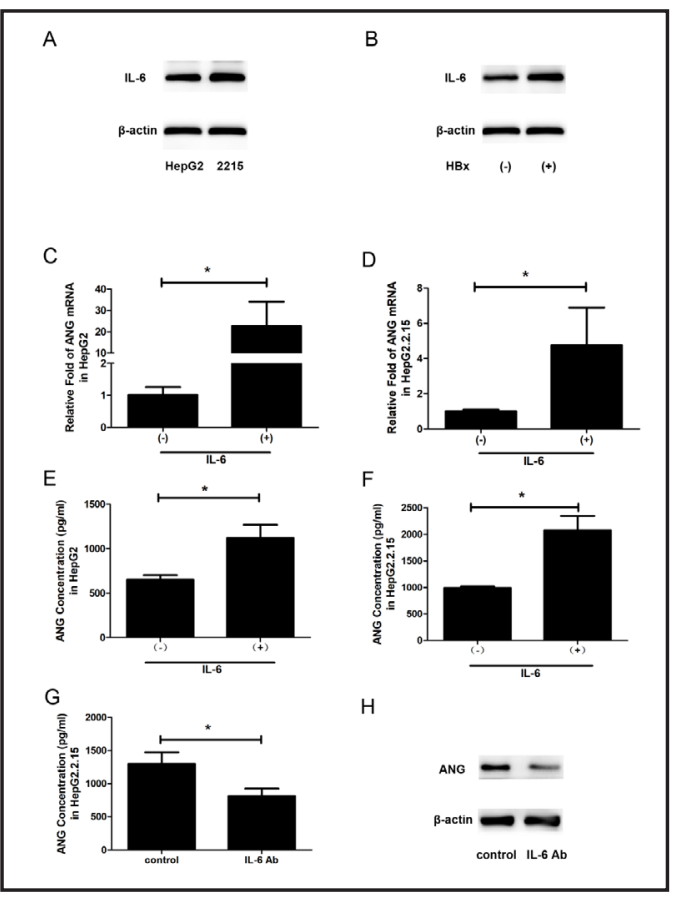

Fig. 4. HBV-induced up-regulation of ANG was depending on IL-6. Protein levels of IL-6 increased in HepG2.2.15 cells (A) and HepG2 cells transfected with HBx plasmid (B). HepG2 cells and HepG2.2.15 cells were treated with recombinant human IL-6 protein (50ng/ml) for $48 \mathrm{hrs}$. ANG mRNA (C and D) was detected by Real-Time PCR, and concentration of ANG in supernatant ( $\mathrm{E}$ and F) was detected by ELISA. HepG2.2.15 cells were then treated with IL-6 neutralizing antibody, the supernatant ANG $(G)$ and intracellular proteins $(H)$ were detected after 48 hrs. ( $\left.{ }^{*} \mathrm{P}<0.05,{ }^{* *} \mathrm{P}<0.01\right)$. 


\section{Cellular Physiology and Biochemistry

$H B V / H B x$ contributed to nuclear transfer of $A N G$

The biological activity of ANG depends on its nuclear transfer. During the normal life cycle, the process of ANG nuclear transfer is under subtle regulation, and this process will decrease with the increase of cell density. In order to explore the biological roles of the high-expressed ANG induced by HBV, subcellular localization of ANG protein was monitored by confocal microscopy. Our data showed that nuclear transfer of ANG in 2215 cells or HepG2-HBx was significantly higher than that in HepG2 cells. Whereas, nuclear transfer of ANG in HepG2 cells showed no statistical difference in the presence of IL-6 (Fig. 5).

\section{Inhibition of $A N G$ can decrease cell proliferation}

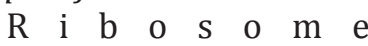
transcription is the basis of cell proliferation regulation. Previous study confirmed that nuclear ANG-promoted ribosome transcription was mainly responsible for ANG-induced prostate cancer development [32]. To investigate the effects of ANG on the synthesis of rRNA in hepatocytes, Real-Time PCR was used to detect the expression of ribosomal 45S rRNA in HepG2.2.15 cells treated with exogenous ANG $(1 \mu \mathrm{g} / \mathrm{ml})$ or ANG siRNA in this study. The results confirmed that ANG could promote the synthesis of 45S rRNA in HCC cells, and inhibition of ANG expression can also inhibit the synthesis of 45S rRNA (Fig. 6A). Similarly, HBx and IL-6 also contributed to 45S rRNA expression (Fig. 6B and 6C). Meanwhile, the proliferation of liver cells treated by ANG siRNA was inhibited (Fig. 7A and 7B). When treated with neomycin $(200 \mu \mathrm{M})$, an inhibitor of ANG nuclear translocation [33], the proliferation of liver cells can be inhibited, while paromomycin serving as a control of neomycin [34] can not inhibit the proliferation (Fig. 7D and 7E). Also, inhibition of IL-6 could attenuate the proliferation of HCC cells (Fig. 7 F and 7G).

\section{Discussion}

ANG, up-regulated in many human cancers [28], can promote tumor angiogenesis and stimulate tumor cells proliferation directly by stimulating the expression of NF- $\kappa \mathrm{B}$ and $\mathrm{Bcl}-$
Fig. 5. HBV promoted and HepG2.2.15 cells were detected by immunofluorescence. (B) ANG localization cells after 6 treted. Cellular ANG was immunostained with anti-ANG antibody, TO-PRO-3 was used to staining the cell nuclear, merge indicated the nuclear translocation of ANG.

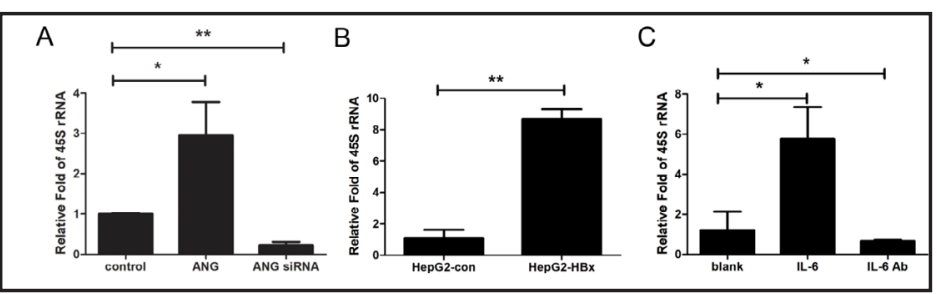

Fig. 6. ANG promoted the synthesis of $45 \mathrm{~S}$ rRNA. HepG2.2.15 cells were transfected with ANG siRNA or control siRNA, after 48 hrs, 45S rRNA were detected by Real-Time PCR (A). (B) 45S rRNA increased in HepG2HBx compared to HepG2-con. (C) IL-6 in HepG2.2.15 cells increase the $45 \mathrm{~S}$ rRNA level and IL-6 antibody decrease. $\left({ }^{*} \mathrm{P}<0.05\right.$, $\left.{ }^{* *} \mathrm{P}<0.01\right)$. (C) ANG 


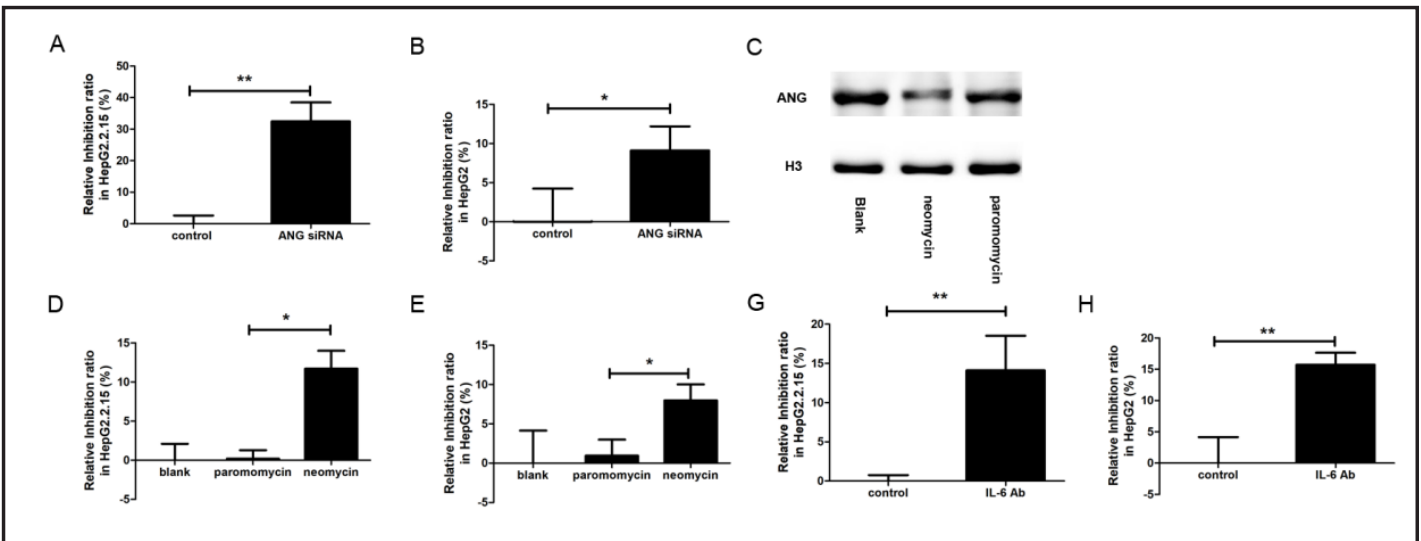

Fig. 7. Inhibition of ANG decreased tumor cells proliferation. Cell proliferation was measured by MTT, the cell inhibition rate showed significant increase when the expression of ANG was inhibited by siRNA (A and B). (C) Western Blot assay of 2215 nucleoprotein after neomycin (200uM) and paromomycin (200uM) treated 5 days. (D and E) Neomycine increased the cell inhibition rate. (F and G) Cell inhibition rate increased after adding IL-6 neutralizing antibody.

2 [35], or promoting rRNA transcription [36]. It is initially identified as an angiogenesis factor, and recently, more attention has been paid on its role of angiogenesis in chronic inflammation during tumorigenesis. In this study, we investigate the regulatory roles of HBV on ANG. Our data showed that HBV/HBx could up-regulate ANG via IL-6, which contributed to the proliferation of tumor cells.

Hepatitis B has been found strongly to be associated with HCC, especially in developing countries [37]. In order to investigate the effects of HBV on ANG, we measured the ANG level in HBV-infected patients. Our data suggested that ANG was up-regulated after HBV infection compared to healthy controls. Additionally, HepG2.2.15 cell, a HCC cell line stably expressing HBV virus particles was used to test ANG mRNA and protein. In vitro experiments confirmed that HBV could also promote the expression of ANG. High ANG expression has been reported to be associated with the pathogenesis of HCC. On one hand, extracellular ANG can activate hepatic stellate cells [38]. On the other hand, nuclear ANG involved in the ribosomal RNA transcription [28]. In this study, our findings may reveal a new mechanism for HBV carcinogenesis through modulating the expression of ANG in vivo.

Several factors were associated with the pathogenesis of HBV-induced HCC, such as the integration of HBV virus into the host genome, activation of host proto-oncogene by HBV, or the interaction of host protein and the protein of HBV (e.g. core protein, pre-S protein and $\mathrm{X}$ protein) [39]. Among these factors, $\mathrm{HBx}$ is of much concern due to its active carcinogenic effects. Here, we demonstrated that HBx contributed to the elevation of ANG, which further confirmed the up-regulatory effects of HBV on ANG.

Inflammatory factors secreted by macrophages and lymphocytes in the tumor immune microenvironment may serve as an important regulator in innate immunity, allowing tumor cells to exert anti-apoptotic and angiogenic effects [40]. As a potent pleiotropic inflammatory cytokine, IL- 6 has been shown to play an important role in the pathogenesis of liver cancer, including stimulating cell proliferation and hepatic remodeling. Additionally, it also plays an important role in the survival of patients received hepatectomy [40-42]. IL-6 is usually elevated in those infected HBV, and is closely related to the pathogenesis of HCC [43]. Moreover, it was reported to involve in the up-regulation of both ANG mRNA and protein [44]. These findings suggested that HBV may contribute to the expression of ANG through modulating the IL- 6 activity. Thus, we measured the IL- 6 level in both HepG2 cells and HepG2.2.15 cells, which indicated that the ANG mRNA and protein levels were up-regulated to some extent. In contrast, the ANG expression was down-regulated after neutralizing its activity with antibody. These results suggested the effects of IL-6, mediated by HBV, were 


\section{Cellular Physiology Cell Physiol Biochem 2018;46:461-470

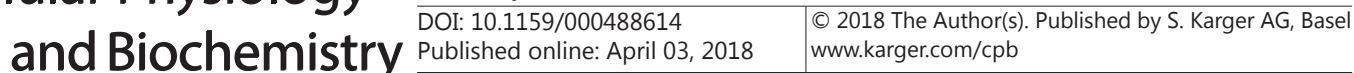 \\ Zhou et al.: HBV Promotes HCC via Angiogenin}

probably responsible for the increased concentration of ANG. Additionally, extensive studies have revealed the role of IL- 6 in the NF- $\kappa$ B pathway $[45,46]$. Simultaneously, ANG can activate NF- $\kappa B$ pathway to inhibit apoptosis [35]. Therefore, we hypothesize that the up-regulation of ANG may promote tumor cell proliferation by positive feedback of NF- $\mathrm{KB} / \mathrm{IL}-6$ pathway.

The roles of ANG in cells are highly depending on its location. In cytoplasm, ANG acts as a RNase cleaving tRNA and producing tRNA-halves, which has been reported to be reduced in liver cancer [47]. In nucleus, ANG is involved in up-regulating rRNA expression [36] or promoting angiogenesis [48], which then stimulates tumor cell proliferation. Under normal conditions, the nuclear translocation of ANG is well regulated. Its nuclear translocation was reported to be reduced in the presence of increased cell density. On this basis, rRNA was kept in balance, in order to guarantee the physiological activities of cells [36]. By subcellular localization of ANG protein, we found that HBV could promote ANG nuclear translocation. Moreover, nuclear ANG could promote 45S rRNA in HepG2.2.15 cells, while increased rRNA transcription might induce aberrant cell proliferation. As high level ANG can promote rRNA transcription and cell proliferation [26], we hypothesize that some strategies may be developed to reduce cell proliferation of HCC cells by inhibiting ANG. To our expectation, 45S rRNA transcription decreased in presence of inhibiting ANG expression using siRNA technique, and cell growth were inhibited at the same time. Similarly, the cellular proliferation was reduced when using neomycine to inhibit the ANG nuclear translocation. These findings suggest that ANG inhibitors may be a promising candidate for treating HBV related HCC.

In summary, we firstly reported that HBV upregulated ANG expression by modulatingIL- 6 expression and ANG nuclear translocation. The cellular proliferation of HCC cells was inhibited in the presence of ANG down-regulation or its nuclear translocation in HBV infected HCC cells. These findings may give a new way to the research and development of drugs for treating HBV related HCC.

\section{Acknowledgements}

The present study was supported by the 12-5 State S\&T Projects of China(No. 2012ZX10002007) , Chinese National Natural and Science Foundation(No.81272674) and the Anhui Provincial Natural Science Foundation (1608085QH172 ).

\section{Disclosure Statement}

No conflict of interests exists.

\section{References}

1 Tacke F, Kroy D C: Treatment for hepatitis B in patients with drug resistance. Ann Transl Med 2016;4:334.

$\checkmark 2$ Ott J J, Stevens G A, Groeger J, Wiersma S T: Global epidemiology of hepatitis B virus infection: new estimates of age-specific HBsAg seroprevalence and endemicity. Vaccine 2012;30:2212-2219.

-3 Tang Z S, Hao Y H, Zhang E J, Xu C L, Zhou Y, Zheng X, Yang D L: CD28 family of receptors on T cells in chronic HBV infection: Expression characteristics, clinical significance and correlations with PD-1 blockade. Mol Med Rep 2016;14:1107-1116.

4 Lok A S, Heathcote E J, Hoofnagle J H: Management of hepatitis B: 2000--summary of a workshop. Gastroenterology 2001;120:1828-1853.

5 Jemal A, Bray F, Center M M, Ferlay J, Ward E, Forman D: Global cancer statistics. CA Cancer J Clin 2011;61:69-90.

6 Patel M, Shariff M I, Ladep N G, Thillainayagam A V, Thomas H C, Khan S A, Taylor-Robinson S D: Hepatocellular carcinoma: diagnostics and screening. J Eval Clin Pract 2012;18:335-342. 


\section{Cellular Physiology Cell Physiol Biochem 2018;46:461-470 and Biochemistry Published online:April 03, $2018 \quad \begin{aligned} & \text { DOI 1018 } 2018 \text { The Author(s). Published by S. Karger AG, Basel } \\ & \text { www.karger.com/cpb }\end{aligned}$ \\ Zhou et al.: HBV Promotes HCC via Angiogenin}

7 Yang J D, Roberts L R: Hepatocellular carcinoma: A global view. Nat Rev Gastroenterol Hepatol 2010;7:448458.

8 Sherlock S, Fox R A, Niazi S P, Scheuer P J: Chronic liver disease and primary liver-cell cancer with hepatitisassociated (Australia) antigen in serum. Lancet 1970;1:1243-1247.

-9 Tarocchi M, Polvani S, Marroncini G, Galli A: Molecular mechanism of hepatitis B virus-induced hepatocarcinogenesis. World J Gastroenterol 2014;20:11630-11640.

10 Wu Z J, Zhu Y, Huang D R, Wang Z Q: Constructing the HBV-human protein interaction network to understand the relationship between HBV and hepatocellular carcinoma. J Exp Clin Cancer Res 2010;29:146.

11 Park S, Lim J, Kim J R, Cho S: Inhibitory effects of resveratrol on hepatitis B virus X-protein (HBx)-induced hepatocellular carcinoma (HCC). J Vet Sci 2017.

12 Geng M, Xin X, Bi L Q, Zhou L T, Liu X H: Molecular mechanism of hepatitis B virus X protein function in hepatocarcinogenesis. World J Gastroenterol 2015;21:10732-10738.

13 Zhang X, Zhang H, Ye L: Effects of hepatitis B virus X protein on the development of liver cancer. J Lab Clin Med 2006;147:58-66.

14 Hou Z, Quan J: Hepatitis B virus X protein increases microRNA21 expression and accelerates the development of hepatoma via the phosphatase and tensin homolog/phosphoinositide 3 kinase/protein kinase B signaling pathway. Mol Med Rep 2017;15:3285-3291.

15 Liu X, Zhang Y, Wang P, Wang H, Su H, Zhou X, Zhang L: HBX Protein-Induced Downregulation of microRNA18a is Responsible for Upregulation of Connective Tissue Growth Factor in HBV Infection-Associated Hepatocarcinoma. Med Sci Monit 2016;22:2492-2500.

16 Gao F, Sun X, Wang L, Tang S, Yan C: Downregulation of MicroRNA-145 Caused by Hepatitis B Virus X Protein Promotes Expression of CUL5 and Contributes to Pathogenesis of Hepatitis B Virus-Associated Hepatocellular Carcinoma. Cell Physiol Biochem 2015;37:1547-1559.

17 Bandopadhyay M, Sarkar N, Datta S, Das D, Pal A, Panigrahi R, Banerjee A, Panda C K, Das C, Chakrabarti S, Chakravarty R: Hepatitis B virus X protein mediated suppression of miRNA-122 expression enhances hepatoblastoma cell proliferation through cyclin G1-p53 axis. Infect Agent Cancer 2016;11:40.

-18 Fett J W, Strydom D J, Lobb R R, Alderman E M, Bethune J L, Riordan J F, Vallee B L: Isolation and characterization of angiogenin, an angiogenic protein from human carcinoma cells. Biochemistry 1985;24:5480-5486.

19 Li S, Ibaragi S, Hu G F: Angiogenin as a molecular target for the treatment of prostate cancer. Curr Cancer Ther Rev 2011;7:83-90.

20 Nilsson U W, Abrahamsson A, Dabrosin C: Angiogenin regulation by estradiol in breast tissue: tamoxifen inhibits angiogenin nuclear translocation and antiangiogenin therapy reduces breast cancer growth in vivo. Clin Cancer Res 2010;16:3659-3669.

-21 Shimoyama S, Shimizu N, Tsuji E, Yamasaki K, Kawahara M, Kaminishi M: Distribution of angiogenin and its gene message in colorectal cancer patients and their clinical relevance. Anticancer Res 2002;22:10451052.

22 Shimoyama S, Kaminishi M: Increased angiogenin expression in gastric cancer correlated with cancer progression. J Cancer Res Clin Oncol 2000;126:468-474.

23 Eberle K, Oberpichler A, Trantakis C, Krupp W, Knupfer M, Tschesche H, Seifert V: The expression of angiogenin in tissue samples of different brain tumours and cultured glioma cells. Anticancer Res 2000;20:1679-1684.

-24 Rozman A, Silar M, Kosnik M: Angiogenin and vascular endothelial growth factor expression in lungs of lung cancer patients. Radiol Oncol 2012;46:354-359.

-25 Hisai H, Kato J, Kobune M, Murakami T, Miyanishi K, Takahashi M, Yoshizaki N, Takimoto R, Terui T, Niitsu Y: Increased expression of angiogenin in hepatocellular carcinoma in correlation with tumor vascularity. Clin Cancer Res 2003;9:4852-4859.

26 Xu Z P, Tsuji T, Riordan J F, Hu G F: The nuclear function of angiogenin in endothelial cells is related to rRNA production. Biochem Biophys Res Commun 2002;294:287-292.

27 Li S, Hu G F: Emerging role of angiogenin in stress response and cell survival under adverse conditions. J Cell Physiol 2012;227:2822-2826. 


\section{Cellular Physiology Cell Physiol Biochem 2018;46:461-470

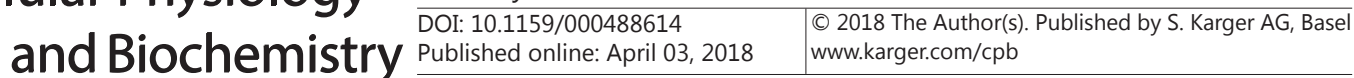 \\ Zhou et al.: HBV Promotes HCC via Angiogenin}

28 Tsuji T, Sun Y, Kishimoto K, Olson K A, Liu S, Hirukawa S, Hu G F: Angiogenin is translocated to the nucleus of HeLa cells and is involved in ribosomal RNA transcription and cell proliferation. Cancer Res 2005;65:1352-1360.

29 Sadagopan S, Sharma-Walia N, Veettil M V, Bottero V, Levine R, Vart R J, Chandran B: Kaposi's sarcomaassociated herpesvirus upregulates angiogenin during infection of human dermal microvascular endothelial cells, which induces $45 \mathrm{~S}$ rRNA synthesis, antiapoptosis, cell proliferation, migration, and angiogenesis. J Virol 2009;83:3342-3364.

-30 Sikriwal D, Seth D, Parveen S, Malik A, Broor S, Batra J K: An insertion in loop L7 of human eosinophilderived neurotoxin is crucial for its antiviral activity. J Cell Biochem 2012;113:3104-3112.

-31 Bedoya V I, Boasso A, Hardy A W, Rybak S, Shearer G M, Rugeles M T: Ribonucleases in HIV type 1 inhibition: effect of recombinant RNases on infection of primary $\mathrm{T}$ cells and immune activation-induced RNase gene and protein expression. AIDS Res Hum Retroviruses 2006;22:897-907.

-32 Sheng J, Yu W, Gao X, Xu Z, Hu G F: Angiogenin stimulates ribosomal RNA transcription by epigenetic activation of the ribosomal DNA promoter. J Cell Physiol 2014;229:521-529.

-33 Hu G F: Neomycin inhibits angiogenin-induced angiogenesis. Proc Natl Acad Sci U S A 1998;95:9791-9795.

34 Bottero V, Sadagopan S, Johnson K E, Dutta S, Veettil M V, Chandran B: Kaposi's sarcoma-associated herpesvirus-positive primary effusion lymphoma tumor formation in NOD/SCID mice is inhibited by neomycin and neamine blocking angiogenin's nuclear translocation. J Virol 2013;87:11806-11820.

-35 Li S, Yu W, Kishikawa H, Hu G F: Angiogenin prevents serum withdrawal-induced apoptosis of P19 embryonal carcinoma cells. FEBS J 2010;277:3575-3587.

-36 Li S, Hu G F: Angiogenin-mediated rRNA transcription in cancer and neurodegeneration. Int J Biochem Mol Biol 2010;1:26-35.

37 Kao J H, Chen D S: Global control of hepatitis B virus infection. Lancet Infect Dis 2002;2:395-403.

-38 Barcena C, Stefanovic M, Tutusaus A, Martinez-Nieto G A, Martinez L, Garcia-Ruiz C, De Mingo A, Caballeria J, Fernandez-Checa J C, Mari M, Morales A: Angiogenin secretion from hepatoma cells activates hepatic stellate cells to amplify a self-sustained cycle promoting liver cancer. Sci Rep 2015;5:7916.

-39 Nishida N: Impact of hepatitis virus and aging on DNA methylation in human hepatocarcinogenesis. Histol Histopathol 2010;25:647-654.

40 Lin W W, Karin M: A cytokine-mediated link between innate immunity, inflammation, and cancer. J Clin Invest 2007;117:1175-1183.

41 Cressman D E, Greenbaum L E, Deangelis R A, Ciliberto G, Furth E E, Poli V, Taub R: Liver failure and defective hepatocyte regeneration in interleukin-6-deficient mice. Science 1996;274:1379-1383.

42 Sheng T, Wang B, Wang S Y, Deng B, Qu L, Qi X S, Wang X L, Deng G L, Sun X: The Relationship Between Serum Interleukin-6 and the Recurrence of Hepatitis B Virus Related Hepatocellular Carcinoma after Curative Resection. Medicine (Baltimore) 2015;94:e941.

-43 Johnson C, Han Y, Hughart N, Mccarra J, Alpini G, Meng F: Interleukin-6 and its receptor, key players in hepatobiliary inflammation and cancer. Transl Gastrointest Cancer 2012;1:58-70.

44 Verselis S J, Olson K A, Fett J W: Regulation of angiogenin expression in human HepG2 hepatoma cells by mediators of the acute-phase response. Biochem Biophys Res Commun 1999;259:178-184.

45 Wang Y, Zhao M, Liu J, Ni J, Jiao Y, Bai C: Up regulation of IL-6 is involved in di (2-ethylhexyl) phthalate (DEHP) induced migration and invasion of non small cell lung cancer (NSCLC) cells. Biomed Pharmacother 2017;89:1037-1044.

46 Phuagkhaopong S, Ospondpant D, Kasemsuk T, Sibmooh N, Soodvilai S, Power C, Vivithanaporn P: Cadmium-induced IL- 6 and IL-8 expression and release from astrocytes are mediated by MAPK and NFkappaB pathways. Neurotoxicology 2017;60:82-91.

47 Selitsky S R, Baran-Gale J, Honda M, Yamane D, Masaki T, Fannin E E, Guerra B, Shirasaki T, Shimakami T, Kaneko S, Lanford R E, Lemon S M, Sethupathy P: Small tRNA-derived RNAs are increased and more abundant than microRNAs in chronic hepatitis B and C. Sci Rep 2015;5:7675.

48 Zhang Y, Xia X, Yan J, Yan L, Lu C, Zhu X, Wang T, Yin T, Li R, Chang H M, Qiao J: Mesenchymal stem cellderived angiogenin promotes primodial follicle survival and angiogenesis in transplanted human ovarian tissue. Reprod Biol Endocrinol 2017;15:18. 